\title{
Adopt the Euro? The GME approach
}

Ferreira, P., A. Dionísio, C. Pires (2010), "Adopt the Euro? The GME approach", Journal of Economic Interaction and Coordination, 5(2), 231-247.

Abstract:

The objective of this paper is to evaluate the degree of financial integration achieved in the European Union based on covered interest parity and using Generalized Maximum Entropy. EU countries are divided into two groups according to their current situation with respect to the adoption of the euro. Financial integration before the adoption of the euro is analyzed for the countries that adopted the euro in 1999. Similarly, current financial integration is evaluated for non-euro EU countries. Besides the importance of comparing the situation of the non-euro EU countries with the situation of the euro EU countries previous to the euro adoption, which may be useful to evaluate an eventual decision of the non-euro members to adopt the euro, it is interesting to analyze the performance of Generalized Maximum Entropy. Generalized Maximum Entropy has the ability to estimate the parameters of a regression model without imposing any constrains on the probability distribution of errors and it is robust even when we have ill-posed problems. Overall our results suggest that the degree of financial integration on non-euro countries is lower than the degree of financial integration that existed among euro adopting countries before the adoption of the euro.

Keywords: Financial integration; Generalized maximum entropy; Timeseries analysis; Ill-posed problems.

DOI: http://dx.doi.org/10.1007/s11403-010-0062-x 